UDC 582.284.3(470.45)

LBC 28.591(2p-4Вог)

\title{
BASIDIOMYCETES BIODIVERSITY IN THE AREA OF IMPACT OF EMISSIONS OF THE VOLGOGRAD ALUMINUM PLANT
}

\author{
Helen A. Oganesyan \\ Volgograd State University, Volgograd, Russian Federation \\ Nadezhda S. Kuragina \\ Volgograd State University, Volgograd, Russian Federation
}

\begin{abstract}
Annotation. There are a large number of operating plants, combines and factories on the territory of Volgograd. Daily they emit tons of pollutants into the atmosphere, such as sulfur dioxide, carbon monoxide, fluoride compounds, nitrogen oxides, inorganic dust, etc. All of them are absorbed by the environment, including mushrooms. It is known that fruiting bodies of fungi accumulate heavy metals from the environment well and are excellent bioindicators. The study of the accumulation of toxic substances in the basidiomes of macromycetes in Volgograd has not previously been carried out. The purpose of our study was to assess the contamination of mushroom fruiting bodies in the sanitary protection zone of the plant by the bioindication method. We used standard methods of field research, microscopic analysis of samples using a Mikmed-5 binocular microscope, a Levenhuk C $510 \mathrm{NG}$ camera and a standard set of reagents ( $5 \%$ alkali solution and Meltzer's reagent for determining the reaction of cell walls to iodine) and the bioindication method with the use of the lower crustaceans Daphnia as a test object. During mycological studies performed in fall-2019 in the study area, 14 species of fungi were identified. As a result of the bioindication research, a macromycete that accumulates harmful substances to a greater extent - Tricholoma equestre (L.) P. Kumm was identified. This species is considered tasty by the inhabitants of the city. The study proves that picking and eating mushrooms from the territory of sanitary protection factories, in particular the Aluminum Plant, is unsafe.
\end{abstract}

Key words: basidiomycetes, aluminum plant, mycobiota, pollution, ecology, emissions, Volgograd, bioindication.

Citation. Oganesyan H.A., Kuragina N.S. Basidiomycetes Biodiversity in the Area of Impact of Emissions of the Volgograd Aluminum Plant. Natural Systems and Resources, 2020, vol. 10, no. 3, pp. 14-18. DOI: https:// doi.org/10.15688/nsr.jvolsu.2020.3.2

УДК 582.284.3(470.45)

ББК 28.591(2p-4Вог)

\section{БИОРАЗНООБРАЗИЕ БАЗИДИОМИЦЕТОВ В ЗОНЕ ВОЗДЕЙСТВИЯ ВЫБРОСОВ АЛЮМИНИЕВОГО ЗАВОДА ГОРОДА ВОЛГОГРАДА}

\author{
Елена Ашотовна Оганесян \\ Волгоградский государственный университет, г. Волгоград, Российская Федерация \\ Надежда Сергеевна Курагина \\ Волгоградский государственный университет, г. Волгоград, Российская Федерация
}

Аннотация. На территории города Волгограда расположено большое количество работающих заводов, комбинатов и фабрик, которые ежедневно выбрасывают в атмосферу тонны загрязняющих веществ, таких как сернистый ангидрид, угарный газ, фтористые соединения, оксиды азота, пыль неорганическую и т. п. Все они впитываются окружающей средой, в том числе и грибами. Известно, что 
плодовые тела грибов хорошо накапливают тяжелые металлы из внешней среды и являются отличными биоиндикаторами. Изучение накопления токсичных веществ в базидиомах макромицетов в г. Волгограде ранее не проводилось. Цель нашего исследования состояла в проведении оценки загрязнения плодовых тел грибов в санитарно-защитной зоне завода биоиндикационным методом. В работе были использованы стандартные методы полевых исследований, микроскопического анализа образцов с применением бинокулярного микроскопа Микмед-5, камерой Levenhuk C 510 NG и стандартного набора реактивов ( 5 \%-ный раствор щелочи и реактив Мельцера для определения реакции клеточных стенок на йод) и метод биоиндикации с использованием в качестве тест-объекта низших ракообразных дафний. В ходе микологических исследований, проводимых осенью 2019 года на исследуемой территории, было выявлено 14 видов грибов. В результате биоиндикационных исследований был выявлен макромицет, который в большей степени накапливает вредные вещества - Tricholoma equestre (L.) P. Kumm. Данный вид считается жителями города очень вкусным. Проведенное исследование доказывает, что сбор и употребление в пищу грибов с территории санитарно-защитных заводов, в частности Алюминиевого завода, небезопасно.

Ключевые слова: базидиомицеты, алюминиевый завод, микобиота, загрязнение, экология, выбросы, Волгоград, биоиндикация.

Цитирование. Оганесян Е. А., Курагина Н. С. Биоразнообразие базидиомецетов в зоне воздействия выбросов алюминиевого завода города Волгограда // Природные системы и ресурсы. - 2020. - Т. 10, № 3. C. 14-18. - DOI: https://doi.org/10.15688/nsr.jvolsu.2020.3.2

Введение. Волгоградский Алюминиевый завод (ВГАЗ), входящий в группу СУАЛ, является седьмым по величине алюминиевым заводом в России. Процесс электролиза глинозема, применяемый на заводе, является источником экологических рисков. В воздушных выбросах ВгАЗа содержится большое количество загрязняющих веществ: фтористый водород, плохо растворимые фториды, смолистые вещества, полициклические ароматические углеводороды, пыль неорганическая. При этом, фтористые соединения являются высоко опасными веществами для живых организмов [6].

Грибы, являющиеся неотъемлемым элементом экосистемы, играют ключевую роль в поглощении элементов в лесной подстилке и почве. В связи с этим изучение возможностей использования макромицетов в качестве индикаторов антропогенной нарушенности в таких индустриальных центрах как Волгоград, с интенсивным ростом промышленности, представляет большой интерес.

Изучение накопления токсичных веществ в базидиомах макромицетов в г. Волгограде ранее не проводилось.

Исходя из вышесказанного, цель работы состояла в проведении оценки загрязнения плодовых тел грибов на территории санитарно-защитной зоны ВгАЗа с применением метода биоиндикации.
Объектом исследования послужили макромицеты санитарно-защитной зоны Алюминиевого завода города Волгограда.

Материал и методы. В ходе полевых исследований проводилось описание макропризнаков грибов, таких как, формы и величины базидиом, вида и окраски гименофора и т. д. Плодовые тела были тщательно высушены, и этикетированы.

Микроскопический анализ и биоиндикация собранного материала проводились на кафедре биологии ВолГУ. Идентифицировались грибы с помощью бинокулярного микроскопа Микмед-5, камерой Levenhuk C 510 NG и стандартного набора реактивов. При определении найденных образцов использовались работы российских и зарубежных микологов [1-5; 7]. Было собрано более 150 образцов грибов, которые хранятся в Микологическом гербарии ВолГУ (VOLSU).

Для определения степени токсичности найденных макромицетов использовали культуру Daphnia magna Straus. Критерием токсичности служило время гибели дафний от воздействия испытуемого экстракта гриба, которое констатируют по полному прекращению их движения [8].

Результаты и обсуждение. В результате проведенных исследований на территории санитарно-защитной зоны ВгАЗа было выявлено 14 видов грибов, относящихся к 13 родам, 9 семействам и 4 порядкам. Пере- 
чень макромицетов, найденных в настоящее время на исследуемой территории, представлен ниже. Названия видов в списке приведены в алфавитном порядке, современные названия грибов представлены в соответствии с международной электронной базой данных CABI «IndexFungorum» (www.indexfungorum.org) по состоянию на октябрь 2020 года. В аннотациях к каждому виду даты сведения о субстрате и гербарных образцах.

\section{Макромицеты санитарно-защитной зоны} ВгАЗа и их субстратная приуроченность

1. Agaricus arvensis Schaeff. - на почве, VOLSU 41.

2. Auricularia mesenterica (Dicks.) Pers.на валежном стволе лиственного дерева, VOLSU 873.

3. Cellulariella warnieri (Durieu et Mont.) Zmitr. et Malysheva [ $\equiv$ Lenzites warnieri Durieu et Mont.] - на валежном стволе лиственного дерева, VOLSU 1219.

4. Cerioporus squamosus (Huds.) Quél. [三 Polyporus squamosus (Huds.) Fr.] - на стволе ослабленного лиственного дерева, VOLSU 1369.

5. Crucibulum laeve (Huds.) Kambly - на валежной ветви лиственного дерева, VOLSU 281.

6. Flammulina velutipes (Curtis) Singer на пне лиственного дерева, VOLSU 921.
7. Gloeophyllum sepiarium (Wulfen) P. Karst. - на валежном стволе лиственного дерева, VOLSU 651.

8. Marasmius oreades (Bolton) Fr. - на почве, VOLSU 155.

9. Marasmius rotula (Scop.) Fr. - на подстилке, VOLSU 290.

10. Parasola conopilea (Fr.) Örstadius et E. Larss. [ $\equiv$ Psathyrella conopilea (Fr.) A. Pearson et Dennis]. - на почве, VOLSU 100.

11. Pseudosperma rimosum (Bull.) Matheny et Esteve-Rav. - на подстилке, VOLSU 157.

12. Trametes ochracea (Pers.) Gilb. et Ryvarden. - на валежном стволе лиственного дерева, VOLSU 1522.

13. Tricholoma equestre (L.) P. Kumm.на почве, VOLSU 1133.

14. Tricholoma saponaceum (Fr.) P. Kumm. - на почве, VOLSU 158.

В проводимом в данной работе биоиндикационном исследовании одним из требований, предъявляемых к видам-индикаторам, является распространенность на исследуемой территории. Согласно шкале встречаемости, регулярно были встречены виды Agaricus arvensis и Tricholoma equestre (больше 25 раз), это и определило наш выбор.

В результате было установлено, что наибольшая смертность дафний (100 \%) наблюдалась в вытяжке гриба Tricholoma equestre, собранном в ельнике на расстоянии 350 метров от ВгАЗа (см. рисунок).

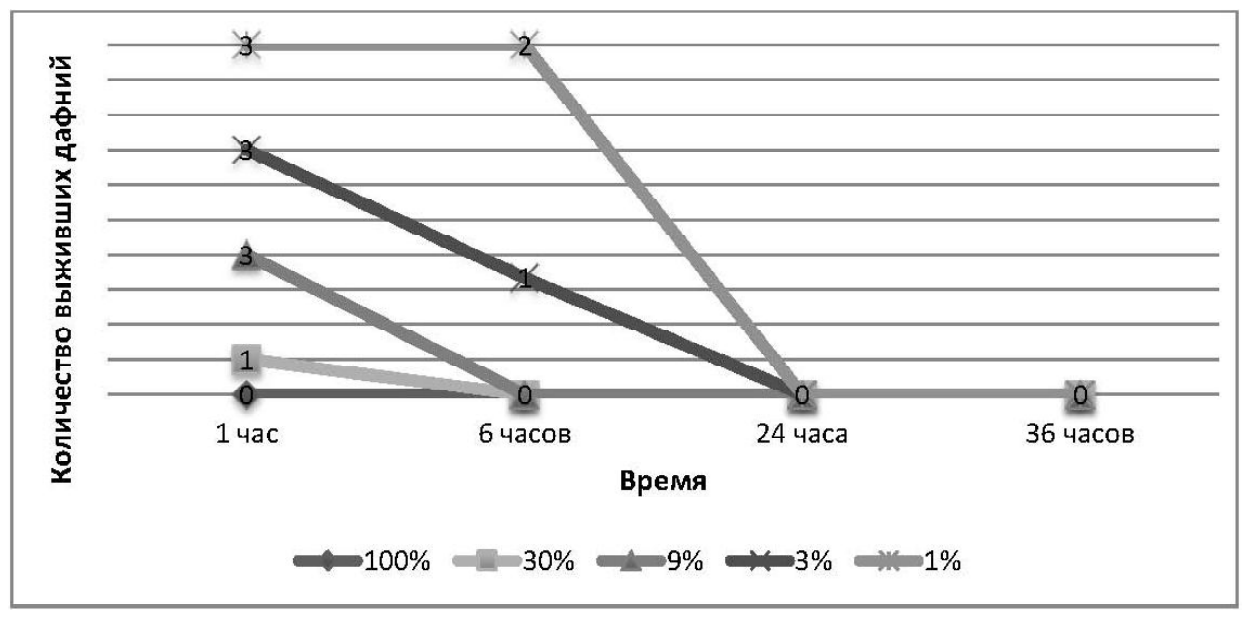

Определение степени загрязнённости плодового тела гриба Tricholoma equestre

Примечание. Разным значком отражены концентрации раствора, в точках отмечено количество выживших дафний. 
Е.А. Оганесян, Н.С. Курагина. Биоразнообразие базидиомецетов в зоне воздействия выбросов

\section{Заключение}

В результате было установлено достоверное воздействие выбросов ВгАЗа на прилегающую экосистему. Представленные результаты являются предварительными, но, тем не менее, показывают перспективность использования грибов в качестве индикаторов антропогенной нарушенности.

\section{БЛАГОДАРНОСТЬ}

Е.А. Оганесян и Н.С. Курагина признательны старшему научному сотруднику ФГБНУ «ВНИРО» М.С. Смолянскому за предоставленную культуру Daphnia magna.

\section{СПИСОК ЛИТЕРАТУРЫ}

1. Антонин, В. Грибы. Большая энциклопедия / В. Антонин, 3. Котлаба, Ф. Клузак. - Издательский Дом Ридерз Дайджест (Португалия), 2005. $320 \mathrm{c}$.

2. Афонькин, С. Ю. Большая иллюстрированная энциклопедия. Грибы России / С. Ю. Афонькин. - Вильнюс : UAB «Bestiary», 2014. - 224 с.

3. Бондарцева, М. А. Определитель грибов России. Порядок афиллофоровые / М. А. Бондарцева - СПб. : Наука, 1998. - 391 с.

4. Гарибова, Л. В. Популярный атлас-определитель. Грибы / Л. В. Гарибова. - М. : Дрофа, 2009. $-350 \mathrm{c}$.

5. Змитрович, И. В. Определитель грибов России. Порядок афиллофоровые / И. В. Змитрович. М. ; СПб. : Товарищество научных изданий КМК, 2008. $-278 \mathrm{c}$.

6. Манаенков, И. В. Влияние деятельности ОАО «Волгоградский алюминий» на содержание тяжелых металлов в почве / И. В. Манаенков, Г. К. Лобачева, Л. Н. Фокина, И. Н. Сапожникова, И. Ж. Гучанова // Альманах. - Волгоград, 2000. - С. 7-24.

7. Переведенцева, Л. Г. Определитель грибов (агарикоидные базидиомицеты) / Л. Г. Переведенцева. - М. : Товарищество научных изданий КМК, 2015. $-119 \mathrm{c}$.
8. ФР.1.39.2007.03221. Методика определения токсичности воды и водных вытяжек из почв, осадков сточных вод, отходов по смертности и изменению плодовитости цериодафний. - М. : Акварос, 2007. $-56 \mathrm{c}$.

\section{REFERENCES}

1. Antonin V., Kotlaba Z., Kluzak F. Griby. Bol'shaja jenciklopedija [Mushrooms. Great Encyclopedia]. Portugal, Izdatelskiy Dom Riderz Daydzhest, 2005. $320 \mathrm{p}$.

2. Afon'kin S.Ju. Bol'shaja illjustrirovannaja jenciklopedija. Griby Rossii [Great Illustrated Encyclopedia. Mushrooms of Russia]. Vilnius, UAB «Bestiary», 2014. $224 \mathrm{p}$.

3. Bondarceva M.A. Opredelitel' gribov Rossii. Porjadok afilloforovye [Keys to Mushrooms of Russia. Order Aphyllophoric]. Saint Petersburg, Nauka Publ., 1998. 391 p.

4. Garibova L.V. Populjarnyj atlas-opredelitel'. Griby [Popular Atlas-Determinant. Mushrooms]. Moscow, Drofa Publ., 2009.350 p.

5. Zmitrovich I.V. Opredelitel'gribov Rossii. Porjadok afilloforovy [Keys to Mushrooms of Russia. Order Aphyllophoric]. Moscow, Saint Petersburg, Tovarishchestvo nauchnykh izdaniy KMK, 2008. 278 p.

6. Manaenkov I.V., Lobachjova G.K., Fokina L.N., Sapozhnikova I.N., Guchanova I.Zh. Vlijanie dejatel'nosti OAO «Volgogradskij aljuminij» na soderzhanie tjazhjolyh metallov v pochve [Influence of the Activity of JSC "Volgograd Aluminum" on the Content of Heavy Metals in the Soil]. Almanah [Almanah]. Volgograd, 2000, pp. 7-24.

7. Perevedenceva L.G. Opredelitel' gribov (agarikoidnye bazidiomicety) [Keys to Fungi (Agaricoid Basidiomycetes)]. Moscow, Tovarishchestvo nauchnykh izdaniy KMK, 2015.119p.

8. FR.1.39.2007.03221. Metodika opredelenija toksichnosti vody $i$ vodnyh vytjazhek iz pochv, osadkov stochnyh vod, othodov po smertnosti $i$ izmeneniju plodovitosti ceriodafnij [FR.1.39.2007.03221. Methods for Determining the Toxicity of Water and Water Extracts from Soils, Sewage Sludge, Waste by Mortality and Changes in Fertility of Ceriodaphnia]. Moscow, Akvaros Publ., $2007.56 \mathrm{p}$. 


\section{ЭколоГия и Биология}

\section{Information About the Authors}

Helen A. Oganesyan, Student, Department of Biology, Volgograd State University, Prosp. Universitetsky, 100, 400062 Volgograd, Russian Federation, praskovya_p@mail.ru

Nadezhda S. Kuragina, Senior Lecturer, Department of Biology, Volgograd State University, Prosp. Universitetsky, 100, 400062 Volgograd, Russian Federation, kuragina23@mail.ru

\section{Информация об авторах}

Елена Ашотовна Оганесян, бакалавр кафедры биологии, Волгоградский государственный университет, просп. Университетский, 100, 400062 г. Волгоград, Российская Федерация, praskovya_p@mail.ru

Надежда Сергеевна Курагина, старший преподаватель кафедры биологии, Волгоградский государственный университет, просп. Университетский, 100, 400062 г. Волгоград, Российская Федерация, kuragina23@mail.ru 